\title{
Influence of Gender and Den Type on Home Range Shape for Striped Skunks, Mephitis mephitis, in Saskatchewan
}

\author{
Serge LariviÈre ${ }^{1,3}$, DAVID Howerter ${ }^{2}$, and FrançOIS Messier ${ }^{3}$ \\ ${ }^{1}$ Delta Waterfowl Foundation, R.R. 1, Box 1, Site 1, Portage La Prairie, Manitoba R1N 3A1 Canada. Present address: Cree Hunters \\ and Trappers Income Security Board, 2700 boulevard Laurier, Champlain \#1110, Québec (Québec) G1V 4K5 Canada \\ ${ }^{2}$ Institute for Wetland and Waterfowl Research, Ducks Unlimited Canada, P.O. Box 1160, Stonewall, Manitoba R0C 2Z0 Canada \\ ${ }^{3}$ Department of Biology, University of Saskatchewan, 112 Science Place, Saskatoon, Saskatchewan S7N 5E2 Canada
}

Larivière, Serge, David Howerter, and François Messier. 2007. Influence of gender and den type on home range shape for Striped Skunks, Mephitis mephitis, in Saskatchewan. Canadian Field-Naturalist 121(3): 261-264.

We investigated gender differences in shape of home ranges for Striped Skunks, Mephitis mephitis, in southcentral Saskatchewan, Canada, during 1993-1994. Data collected on free-ranging Striped Skunks indicated that shape of female home ranges was unaffected by den type (building versus burrow) and was similar to shape of male home ranges. Moreover, type of maternity den did not influence the position of the den within the home range (inside or outside of core area). We conclude that the distribution of Striped Skunks in summer, and the distribution of their foraging activity, are not affected by the availability of anthropogenic den structures.

Key Words: Striped Skunk, Mephitis mephitis, home range, denning site, spatial distribution, Canadian prairies.

Fragmentation of habitats affects not only how animals are distributed in the landscape, but also their use of space. In fragmented landscapes, suitable habitats for foraging may not occur in proximity to other critical habitats for denning, parturition, or rearing of young. Therefore, mammalian females that live in fragmented landscapes face two problems: establishing a home range that includes suitable foraging habitat and finding a site for parturition and rearing of young.

For males that do not provide parental care, obtaining food is a primary drive affecting behavior during summer. In contrast, females give birth and raise a litter during the same period, and habitat preferences for raising young may not coincide with good foraging habitats. In fragmented landscapes, the compromise between optimal foraging and optimal rearing habitats may affect the establishment of home ranges, and consequently their shape. Thus, the location of maternity dens may have several implications for the distribution of foraging activity of females.

First, den location may affect the shape of the home range or the position of the den site within the home range. For example, species that rely on a burrow and central place for refuge and storage of food may benefit from a centrally located den and circular home range (Bowers 1995). However, in fragmented landscapes, females may have to prioritize either establishment of home range (find a good foraging area first, then find a suitable place to rear young within the home range), or the establishment of maternity den (find a good den first, then find a good place to forage).

We investigated the influence of gender and den types on home range shape of Striped Skunks (Mephitis mephitis) in the parklands of Saskatchewan, Canada. Striped Skunks are distributed across most of Canada and the United States (Rosatte and Larivière 2003).
Females give birth in mid-May, and because males provide no parental care, the progeny are dependent on the mother until mid-July, when the young disperse (Larivière and Messier 1997). In Saskatchewan, female Striped Skunks use two main types of shelter for maternity dens, either anthropogenic structures (e.g., buildings, ca. $60 \%$ of maternity dens) or underground burrows (ca. $40 \%$ of maternity dens) (Larivière and Messier 1998c). The distribution and availability of both den types differ, and thus, we hypothesized that den type could influence home range shape. For example, buildings may provide good denning structure, but their position may not be in proximity to good foraging areas, a scenario that would yield an elongated home range. In contrast, a burrow may be dug presumably closer to good foraging areas, and thus home range of females using burrows could be more circular in shape. Thus, Striped Skunks provide a good model species to test predictions of den site positioning and home range shape by animals occupying fragmented landscapes.

\section{Study Area and Methods}

We conducted this study in the Prairie Pothole Region of southcentral Saskatchewan $\left(52^{\circ} 45^{\prime} \mathrm{N}, 107^{\circ} 08^{\prime} \mathrm{W}\right)$. Small grain (i.e., wheat, barley, oats) and oil crops (mostly canola but also flax) occupy $60 \%$ of the landscape. Numerous wetlands and stands of Trembling Aspen (Populus tremuloides) occur throughout the area. Topography is gently rolling, and an extensive network of roads divides the land. Areas managed for nesting waterfowl are common throughout the area, and consist mostly of dense nesting cover, a mixture of native and tame grasses seeded specifically to attract upland nesting waterfowl. General characteristics of the Prairie Pothole Region are detailed elsewhere (Greenwood et al. 1995). 
From April to August, 1993-1994, Striped Skunks were captured in opaque-sided livetraps (Larivière and Messier 1999) and anesthetized using halothane and Telazol® (Larivière and Messier 1996a). All individuals were equipped with a 5 -sec delay motion-sensitive radio-collar (150-152 Mhz, Telonics Inc., Mesa, Arizona, USA) to monitor activity during tracking (Larivière and Messier 1997). Skunks were released at the site of capture.

Radio-collared animals were located by an observer using hand-held receiving equipment from 18:00 to 06:00, during the period of greatest activity (Larivière and Messier 1997). Individuals were located every 15 min by direct observation, auditive location, or shortrange $(<50 \mathrm{~m})$ triangulation (Larivière and Messier 1998b). Light amplifying, night-vision goggles (ANPVS 5, Bill's Electronics Ltd., Mildmay, Ontario) enabled visual observations at night. Tracking effort was systematically distributed among all skunks, and no animals were tracked during two consecutive nights. Striped Skunks exhibit aposematic behavior, and defensive postures are obvious (Larivière and Messier 1996b). Locations immediately following an observerinduced defensive posture were discarded from analyses due to possible observer disturbance (Larivière and Messier 1998b).

Universal Tranverse Mercator coordinates were obtained from the exact location of the skunk following its departure from the area using a portable Global Positioning System (Ensign GPS, Trimble Navigation, Cansel Survey Equipment, Burnaby, British Columbia). To increase the precision of the coordinates, we only considered locations for which $\geq 3$ satellites were available (D'Eon 1995).

Our radio-tracking schedule was intensive (i.e., locations every $15 \mathrm{~min}$ ), and designed to maximize direct behavioral information instead of statistical independence within an animal's home range. Using Shoener's ratio, we estimated that statistical independence between locations occurred at intervals of $270 \mathrm{~min}$. However, Striped Skunks are highly mobile, and are capable of moving $>1 \mathrm{~km}$ in $15 \mathrm{~min}$, even in dense vegetation (Larivière and Messier 1998b). Thus, we assumed that short movements reflected behavioral decisions by the skunk, not physical constraints.

We defined maternity dens as any sites for which at least two of the following criteria were satisfied: repeated use for $>3$ consecutive days during the parturition/rearing period (15 May - 30 June), collection of grass for preparation of nest chamber, or presence of young during the rearing period (Larivière and Messier 1998a). Because some females may relocate their progeny during the rearing period, and because we could not assess why females changed maternity dens (e.g., to reduce parasite loads, disturbance, relocation to a better foraging area, etc.), we only used data on females with a single maternity den for spatial analysis of den locations within home ranges.
Our entire study area was digitized into a Geographic Information System (SPANS GIS, PCI Geomatics, Richmond Hill, Ontario, Canada). Locations of the maternity dens were plotted for all female skunks, as well as all telemetry locations to determine home range size (Larivière and Messier 1998c) and shape. Home range shape was quantified using a shape index (McGarigal and Marks 1994) that was calculated by the following formula:

shape index $=$ perimeter $/(2 * \sqrt{ }(\mathrm{pi} *$ area $))$.

Thus, a smaller shape index indicates a more circular range. We compared average shape indices for males and females with a Student $t$-test for unpaired samples. Spatial analyses of activity centres were performed using software package TRACKER and RANGES IV, and core areas (50\% minimum convex polygon; Larivière and Messier 1998c) were considered activity centers (Samuel et al. 1985).

\section{Results}

In 1993 and 1994, we radiotracked Striped Skunks during 1858 hours, and obtained home range information for 20 females and 5 males. Of the 20 females, 11 used only 1 maternity den during the entire period.

First, we predicted that because of the fixed position of buildings in the landscapes, females using buildings as maternity dens would have home ranges less circular (larger shape index) than those using burrows. This prediction was not supported by our data: the shape index of females using buildings (mean $=1.53, \mathrm{SE}=0.08$, $n=6$ ) did not differ (one-tailed $t=0.45, \mathrm{df}=9, P=0.33$ ) from the shape index of females using burrows as maternity dens $($ mean $=1.48, \mathrm{SE}=0.07, n=5)$.

Second, we hypothesized that if females try to minimize the travel distance to any point within their respective home ranges due to lactation constraints, then home range of females should be more circular (smaller shape index) than home ranges of males. Our prediction that home ranges of females are more circular than those of males was not supported: the average shape index for females (mean $=1.46, \mathrm{SE}=0.03$, $n=20$ ) did not differ (two-tailed $t=0.59, \mathrm{df}=23$, $P=0.56)$ from the average shape index of male home ranges $($ mean $=1.50, \mathrm{SE}=0.06, n=5)$.

Third, we hypothesized that because buildings are preferred denning sites (Larivière and Messier 1998a), some buildings may be used as maternity dens but not be located within the core area of the home range. We predicted that underground burrows should occur in the core areas more often than dens in buildings. Our data also did not support this prediction: there were no associations between den type and whether or not the den was located inside the core area $(n=12 \mathrm{fe}-$ males; Fisher exact test, $P=0.52$ ). Overall, three underground burrows were inside versus two outside the core area, whereas six buildings were inside versus one outside the core area. In total, $75 \%$ of dens were inside core areas. 
In this study, we did not detect any effect of den type (anthropogenic or not) on shape of female home ranges or position of the den. Further, the shape of Striped Skunk home ranges was similar among males and females. These findings suggest that female skunks establish home ranges irrespective of den type and with rules similar to males.

Examination of the natural history of Striped Skunks may help explain the patterns observed. First, Striped Skunks in northern environments undergo long periods of inactivity during winter, and to survive such period requires sufficient body reserves (Gunson and Bjorge 1979; Hwang et al. 2007; see also Rogers 1987). Thus, establishing a home range that includes good foraging areas may be more critical than choice of maternity den, but whether choice of maternity den influences juvenile survival remains unknown. In our study area, many buildings that were deemed suitable for occupation by skunks were not utilized (Larivière et al. 1999). As well, numerous females that used underground burrows to rear young had suitable unoccupied buildings within the boundaries of their home ranges. Thus, although buildings may be convenient denning sites, they may not be necessary or provide reproductive advantages to Striped Skunks. If juvenile mortality in skunks mostly occurs after emergence, then anthropogenic den types such as buildings may be used for other reasons such as thermoregulation, protection from the elements, or simply convenience.

During the parturition/rearing period of Striped Skunks, females make nocturnal foraging trips but return to the maternity den by morning to nurse the young (Larivière and Messier 1997). Foraging movements are highly variable $(0-20 \mathrm{~km}$ per night; Larivière et al. 1998b) and highly opportunistic, although mostly focused on insects and small mammals (Greenwood et al. 1999) and targeted to specific habitats (Bixler and Gittleman 2000; Larivière and Messier 2000). Moreover, habitat availability around used and unused buildings in our study area was similar, suggesting that distribution of resources may not affect location of maternity dens, and conversely that choice of maternity den does not affect access to resources. Suitable den sites likely were not limiting for Striped Skunks (Larivière et al. 1999). The preference of Striped Skunks for buildings may be most obvious where buildings are abundant, but absence of buildings as maternity dens probably does not affect distribution of skunks in the landscape during summer. Hence, our study reinforces the previous suggestion that food, instead of denning structures, probably affects distribution of Striped Skunks and their foraging activity in the landscape.

\section{Acknowledgments}

This study was financed by Ducks Unlimited Canada (Institute for Wetland and Waterfowl Research), the Canadian Wildlife Service, and logistic support from Delta Waterfowl Foundation. SL is grateful to
Fonds pour la Formation de Chercheurs et l'Aide à la Recherche (FCAR), Québec, for postgraduate and postdoctoral support, as well as to the National Science and Engineering Research Council for an operating research grant. Technical assistance was provided by B. Dinter, E. Howard, G. Poon, L. R. Walton, B. Fry, and D. Anderson. W. A. Gorsuch reviewed an earlier draft of this manuscript. Methods used in this study were approved by the University of Saskatchewan Animal Care Committee (Approval \#920091).

\section{Literature Cited}

Bixler, A., and J. L. Gittleman. 2000. Variation in home range and use of habitat in the striped skunk (Mephitis mephitis). Journal of Zoology (London) 251: 525-533.

Bowers, M. A. 1995. Use of space and habitats by the eastern chipmunk, Tamias striatus. Journal of Mammalogy 76: 1221.

D'Eon, S. P. 1995. Accuracy and signal reception of a handheld Global Positioning System (GPS) receiver. Forestry Chronicle 71: 192-196.

Greenwood, R. J., A. B. Sargeant, D. H. Johnson, L. M. Cowardin, and T. L. Shaffer. 1995. Factors associated with duck nest success in the prairie pothole region of Canada. Wildlife Monographs 128: 1-57.

Greenwood, R. J., A. B. Sargeant, J. L. Piehl, D. A. Buhl, and B. A. Hanson. 1999. Foods and foraging of prairie striped skunks during the avian nesting season. Wildlife Society Bulletin 27: 823-832.

Gunson, J. R., and R. R. Bjorge. 1979. Winter denning of the striped skunk in Alberta. Canadian Field-Naturalist 93: 252-258.

Hwang, Y. T., S. Larivière, and F. Messier. 2007. Energetic significance and ecological consequences of heterothermy and social thermoregulation in striped skunks (Mephitis mephitis). Physiological and Biochemical Zoology 80: 138-145.

Larivière, S., and F. Messier. 1996a. Immobilization of striped skunks using Telazol®. Wildlife Society Bulletin 24: 713-716.

Larivière, S., and F. Messier. 1996b. Aposematic behavior in the striped skunk, Mephitis mephitis. Ethology 102: 986992.

Larivière, S., and F. Messier. 1997. Seasonal and daily activity patterns of striped skunks (Mephitis mephitis) in the Canadian prairies. Journal of Zoology (London) 243: 255-262.

Larivière, S., and F. Messier. 1998a. Denning ecology of the striped skunk in the Canadian prairies: implications for waterfowl nest predation. Journal of Applied Ecology 35: 207-213.

Larivière, S., and F. Messier. 1998b. The influence of closerange radio-tracking on the behaviour of free-ranging striped skunks, Mephitis mephitis. Canadian Field-Naturalist 112: 657-660.

Larivière, S., and F. Messier. 1998c. Spatial organization of a prairie striped skunk population during the waterfowl nesting season. Journal of Wildlife Management 62: 199204.

Larivière, S., and F. Messier. 1999. Review and perspective of methods used to capture and handle skunks. Pages 141-154 in Mammal Trapping. Edited by G. Proulx. Alpha Wildlife Research and Management Ltd., Sherwood Park, Alberta, Canada. 
Larivière, S., and F. Messier. 2000. Habitat selection and use of edges by prairie striped skunks: implications for duck nest predation. Canadian Journal of Zoology 78: 366-372.

Larivière, S., L. R. Walton, and F. Messier. 1999. Selection by striped skunks (Mephitis mephitis) of farmsteads and buildings as denning sites. American Midland Naturalist 142: 96-101.

McGarigal, K., and B. J. Marks. 1994. FRAGSTATS: spatial pattern analysis program for quantifying landscape structure. Version 2.0. Forest Science Department, Oregon State University, Corvallis, Oregon, USA.
Rogers, L. L. 1987. Effects of food supply and kinship on social behaviour, movements, and population growth of black bears in northeastern Minnesota. Wildlife Monographs 97: 1-72.

Rosatte, R., and S. Larivière. 2003. Skunks. Pages 692707 in Wild mammals of North America: biology, management, and economics. Edited by G. A. Feldhamer, B. Thompson, and J. A. Chapman. Johns Hopkins University Press, Baltimore.

Samuel, M. D., D. J. Pierce, and E. O. Garton. 1985. Identifying areas of concentrated use within the home range. Journal of Animal Ecology 54: 711-719.

Received 18 April 2006

Accepted 7 July 2008 